\title{
LA TEMPERATURA DE LA SUPERFICIE DEL MAR PERUANO A PARTIR DE LAS IMÁGENES AVHRR / NOAA (2000 - 2003)
}

\author{
Joel Rojas Acuña, y José Carlos Eche Llenque \\ Laboratorio de Teledetección, Departamento de Física Interdisciplinaria, \\ Facultad de Ciencias Físicas, Universidad Nacional Mayor de San Marcos. Lima-Perú. \\ Apartado Postal 14-0149, Lima 14 - Perú.
}

\begin{abstract}
Resumen
El objetivo de este trabajo es el análisis de la temperatura de la superficie del mar (TSM), estimado de los datos AVHRR / NOAA, cerca de la costa Peruana para su aplicación en la determinación de los frentes térmicos y en el estudio del Fenómeno El Niño. El área de estudio se ubica entre las coordenadas geográficas, esquina superior izquierda $\left(90^{\circ} \mathrm{W}, 0^{\circ} \mathrm{S}\right)$ y esquina inferior derecha $\left(70^{\circ} \mathrm{W}, 20^{\circ} \mathrm{S}\right)$. Los datos imágenes originales level 1b LAC y GAC del sensor AVHRR de la serie de satélites de orbita polar NOAA han sido obtenidos de los archivos de la NOAA. El software Pacha Ricaj ha sido diseñado para leer y visualizar la imagen original, invertir, ejecutar la corrección geométrica, calcular la TSM y filtrar nubes. Los resultados obtenidos son las imágenes de la TSM diaria y mensual.
\end{abstract}

En la costa del litoral peruano, la TSM es menor en magnitud $\left(\sim 10^{\circ}\right.$, cerca de Paracas) que en la parte mas alejada de la costa $\left(30^{\circ}\right.$, costa norte). En estas imágenes se ha observado muchas nubes sobre el mar y sobre tierra que han impedido determinar la TSM. Las TSM obtenidas por satélite han sido validadas con las TSM medidas in situ por el Instituto del Mar del Perú (IMARPE) para el periodo de agosto a noviembre del 2002. Se ha calculado bias de $+1.6 \%$ y un rmsd de $1.07^{\circ} \mathrm{C}$ para estos datos.

Palabras claves: TSM, Split Windows, AVHRR, Pacha Ricaj, validación.

\begin{abstract}
The objective of this work is the analysis of the sea surface temperature (SST), estimating of the NOAA / AVHRR data, near the Peruvian coast for their application in the determination of the thermal fronts and in the study of El Niño phenomenon. The study of area is location between the geographies coordinate, $\left(90^{\circ} \mathrm{W}, 0^{\circ} \mathrm{S}\right)$ left upper corner and $\left(70^{\circ} \mathrm{W}, 20^{\circ} \mathrm{S}\right)$ right lower corner. The crude image data level $1 b$ LAC and GAC from AVHRR sensor of the NOAA polar orbit satellite's series has been derived of the NOAA archive active. The Pacha Ricaj software has been designed for read and display the crude image, inverse, geometric corrections execute, cloud filter and SST estimate. The resulting derives are the diary and monthly SST images.

In the Peruvian coast, the SST is less in magnitude than off the coast. In this imagines has been observed many cloud over sea and land that have disabled SST estimated. A bias of $+1.6 \%$ has been calculated and $1.07{ }^{\circ} \mathrm{C}$ of RMSD for this data set.
\end{abstract}

Keywords: Sea surface temperature, Split Windows, AVHRR, Pacha Ricaj, validation. 


\section{Introducción}

Conocer la distribución espacio temporal del campo temperatura de la superficie del mar (TSM) en toda la Tierra es de significativa importancia para la comunidad científica [1] Esta información es particularmente útil en la localización de frentes térmicos, las corrientes de los océanos, y el intercambio de energía térmica entre el océano y la atmósfera. En general, a mayor precisión en el conocimiento de la distribución de la temperatura más alto es el costo para lograr este objetivo. [2] ha expresado que las estimaciones de la temperatura relativa dentro de $\pm 1^{\circ} \mathrm{C}$ en una resolución espacial de aproximadamente $1.1 \mathrm{~km}$ seria satisfactorio. Las medidas de TSM a partir del sensor AVHRR a bordo del satélite NOAA revelan una alta variabilidad a mesoescala de la circulación oceánica. A partir de la TSM se detectan frentes térmicos que están asociados con las corrientes oceánicas superficiales. La principal ventaja que se consigue con datos de satélite es la medición de los campos geofísicos con una amplia cobertura espacial, en una sola observación se consigue observar estructuras térmicas características de la superficie del mar y una secuencia temporal de estas observaciones nos permite observar su evolución. Las imágenes obtenidas en la región del infrarrojo del espectro electromagnético son confiables para el estudio de corrientes oceánicas y nos permite observar su evolución. El objetivo principal de este trabajo es la estimación de la temperatura superficial del mar cerca de Perú en el Océano Pacifico Oriental $\left(90^{\circ} \mathrm{W}\right.$, a $70^{\circ} \mathrm{W}$ en longitud y de $0^{\circ}$ a $20^{\circ} \mathrm{S}$ en latitud) usando imágenes del sensor AVHRR del satélite de orbita polar NOAA. Un objetivo secundario es su aplicación en la determinación de los frentes térmicos y en el estudio del Fenómeno El Niño. Los datos imágenes originales en formato Level $1 \mathrm{~b}$ del sensor AVHRR del satélite NOAA fueron obtenidas de los archivos de la NOAA en Estados Unidos. La recolección de datos imágenes, y el procesamiento de las imágenes han sido realizados en el Laboratorio de Teledetección (LABTEL) de la Facultad de Ciencias Físicas, Universidad San Marcos. Los algoritmos para obtener TSM han sido integrados en el software de procesamiento de imágenes NOAA diseñado en el LABTEL llamado "Pacha Ricaj". La presencia de nubes en las imágenes es uno de los principales problemas en el calculo de TSM, en este caso los píxeles con nubes o parcialmente nubosos son filtrados con la técnica de umbrales utilizando los canales 1 y 5, para eliminar el problema en los bordes de las nubes se ha aplicado el algoritmo GRASA (Great Rapid Algorithm for Sourring Area) [3]. La TSM ha sido obtenida usando el modelo "Split Window", que utiliza la banda $4(10.30-11.30 \mu \mathrm{m}) \quad$ y la banda $5(11.50-12.50 \mu \mathrm{m})$ [4,5]. Los resultados obtenidos son imágenes de la temperatura superficial del mar diarios y compuestos mensuales con una resolución espacial de $1,1 \mathrm{~km}$ y $4,4 \mathrm{~km}$ en intervalos de $0.1{ }^{\circ} \mathrm{C}$. La TSM medida han sido validados con las medidas in situ en el periodo de agosto hasta noviembre 2002. las medidas in situ han sido obtenidas del Instituto del Mar del Perú a través de una campaña de medición del BAP Humboldt y Olaya [6].

\section{Calibración de los canales infrarrojos térmicos 3b, 4 y 5}

Comenzando con el satélite NOAA-15, en los datos Level $1 \mathrm{~b}$ se incorpora las correcciones de radiancia no lineal para los canales térmicos 4 y 5 del AVHRR/NOAA-16. La radiancia de la escena de la Tierra $\mathrm{N}_{\mathrm{E}}$ en unidades $\mathrm{W} /\left(\mathrm{m}^{2}\right.$-sr$\mathrm{cm}^{-1}$ ) esta dada por la ecuación:

$$
N_{E}=a_{0}+a_{1} C_{E}+a_{2} C_{E}^{2} .
$$

Donde $\mathrm{C}_{\mathrm{E}}$ es la cuenta en 10 bits. Los coeficientes se encuentran almacenados en los datos level 1b. Para convertir el valor de la radiancia, de la escena de la Tierra, medida, $\mathrm{N}_{\mathrm{E}}$, en temperatura de un cuerpo negro equivalente, $\mathrm{T}_{\mathrm{E}}$, se usa el proceso de dos pasos definido por las ecuaciones:

$$
\begin{aligned}
T_{E}^{*} & =\frac{c_{2} v_{c}}{\left\lceil\left[1+\left(\frac{c_{1} v_{c}{ }^{3}}{N_{E}}\right)\right]\right.} \\
T_{E} & =\frac{T_{E}{ }^{*}-A}{B}
\end{aligned}
$$

Los valores para $v_{\mathrm{c}}$ y los coeficientes A y B son encontrados en el apéndice D de la Guía NOAA KLM. Las constantes para convertir la radiancia a temperatura de cuerpo negro son también 
encontrados en el cabecero de Level 1b LAC. $[7,8]$

\section{Datos imágenes y su procesamiento}

\subsection{Datos}

Los datos usados son las imágenes AVHRR / NOAA recolectadas del Instituto del Mar de Perú (IMARPE) y del archivo de imágenes de la NOAA. Las coordenadas limites para imágenes GAC y LAC son de $0^{\circ}$ a $-20^{\circ}$ latitud y de $70^{\circ}$ a $90^{\circ}$ en longitud con una tamaño de 2000 x 2000 píxeles para el LAC y de 500 x 500 píxeles para el GAC.

\subsection{Análisis y Procesamiento de las imágenes}

El software Pacha Ricaj, que significa "Mirando la Tierra" en idioma quechua, ha sido utilizado en este trabajo. Los autores del software son miembros del Laboratorio de Teledetección [1,9, 10]. Este software ha sido desarrollado para procesar imágenes originales Level 1B del sensor AVHRR de los satélites NOAA 14, 15, 16 y 17. Se han implementado varias funciones que permiten desarrollar el procesamiento de las imágenes AVHRR / NOAA de una manera eficiente y rápida. En la Figura 1(a), se muestra la ventana principal del software Pacha Ricaj. Con este software se obtiene la TSM con resolución espacial $1,1 \mathrm{~km}$ en el nadir para imágenes tipo LAC y $4,4 \mathrm{~km}$ para imágenes tipo GAC.

El software permite visualizar imágenes LAC y GAC Level 1b (NOAA 14, 15, 16 y 17). Ingresando en el menú Procesamiento y seleccionando TSM se puede elegir el tipo de algoritmo a utilizar en el cálculo de temperatura superficial del mar. Tres algoritmos son implementados. El algoritmo de Split window es útil cuando la imagen es diurna y el Triple Window cuando la imagen es nocturna. El resultado de aplicar esta función es la temperatura de la superficie mostrada en la siguiente Fig. 1b. Con el software Pacha Ricaj se puede obtener la TSM para imágenes GAC con una resolución espacial de $4 \mathrm{~km}$ y para imágenes LAC con una resolución espacial de $1 \mathrm{~km}$ de los satélites NOAA 14, 15, 16 y 17. La imagen TSM es corregida geométricamente en proyección geográfica en las coordenadas geográficas y tipo de remuestreo que el usuario desee. El resultado es la imagen TSM corregida geométricamente mostrada en la Fig. 1(b). Una de las principales características encontradas en las imágenes sobre el Perú es la gran cantidad de nubes que cubren la superficie terrestre. El software implementado permite obtener una mascara de nubes a partir de las bandas 1 y 5 para cada imagen de tal manera que las cuentas digitales de los píxeles afectados por las nubes sean filtradas. Adicionalmente es posible superponer a la imagen producto un vector de costa y una paleta de colores.

\section{Resultados}

En la Fig. 2 se muestran imágenes TSM del NOAA-14 con resolución espacial de $2.2 \mathrm{~km}$. y $4.4 \mathrm{~km}$, respectivamente. La Figura 2(a) muestra la imagen TSM promedio del mes de enero 1999 obtenido a partir de imágenes LAC y con una resolución espacial de $2.2 \mathrm{~km}$. A escala global la imagen TSM promedio muestra aguas frías $(\sim 10$ ${ }^{\circ} \mathrm{C}$ ) en la zona costera, debido al fenómeno de afloramiento costero o de aguas provenientes del sur, con temperaturas que van desde $\operatorname{los} 15{ }^{\circ} \mathrm{C}$ hasta los $20{ }^{\circ} \mathrm{C}$. Además se pueden observar aguas calientes provenientes del ecuador con temperaturas que van desde $22{ }^{\circ} \mathrm{C}$ hasta $27{ }^{\circ} \mathrm{C}$ en zonas alejadas de la costa.

Por ultimo se observa que en la parte sur y alejada de la costa aun se mantienen las temperaturas frías características de la zona sur. La Fig. 2(b) muestra la imagen TSM compuesto del mes de enero de 1999 obtenido a partir de imágenes GAC y con una resolución espacial de $4.4 \mathrm{~km}$. Para la validación de los resultados se han utilizado los datos de TSM obtenidos en mediciones realizadas in situ por el Instituto del Mar del Perú [6] a bordo de los BAP Olaya y Humboldt en el periodo correspondiente al mes de octubre 2002.

Los valores de TSM obtenidos in situ (679 datos) han sido comparados con el valor compuesto mensual para el mes y el año en cuestión para una posición determinada de latitud longitud. 


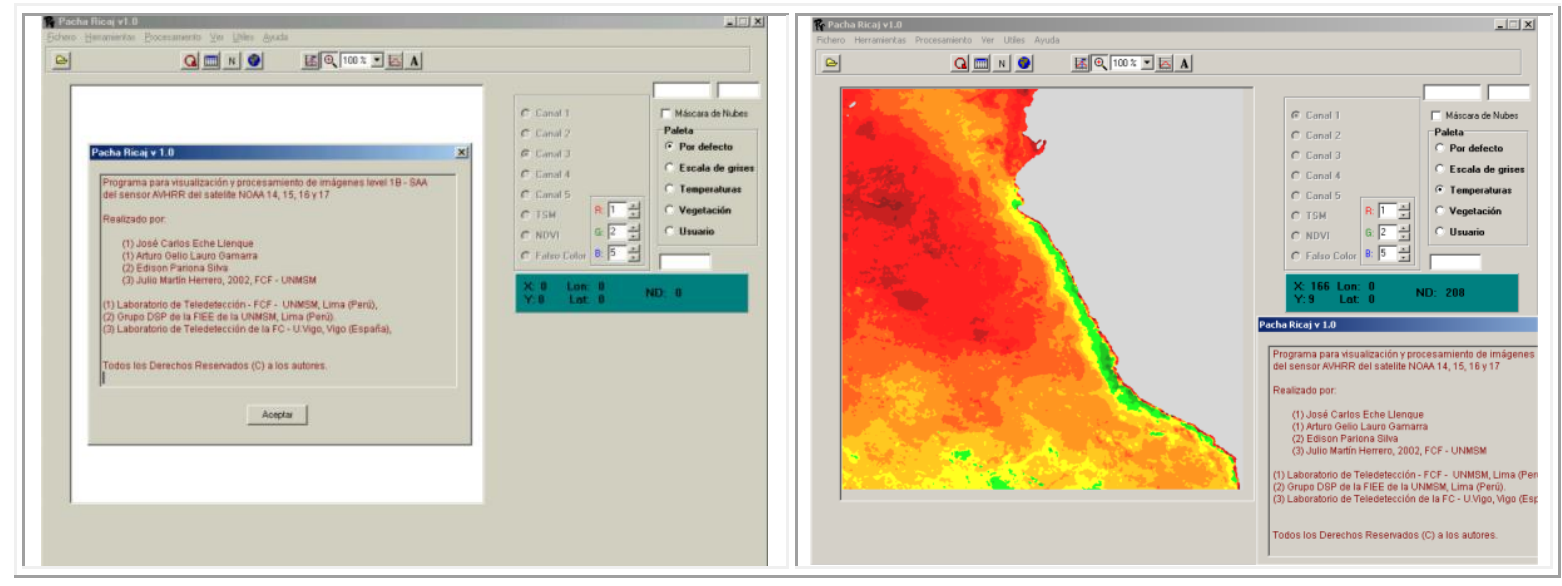

Fig. 1. (a) Ventana principal del software Pacha Ricaj (panel izquierda) (b) Imagen TSM (panel derecha).

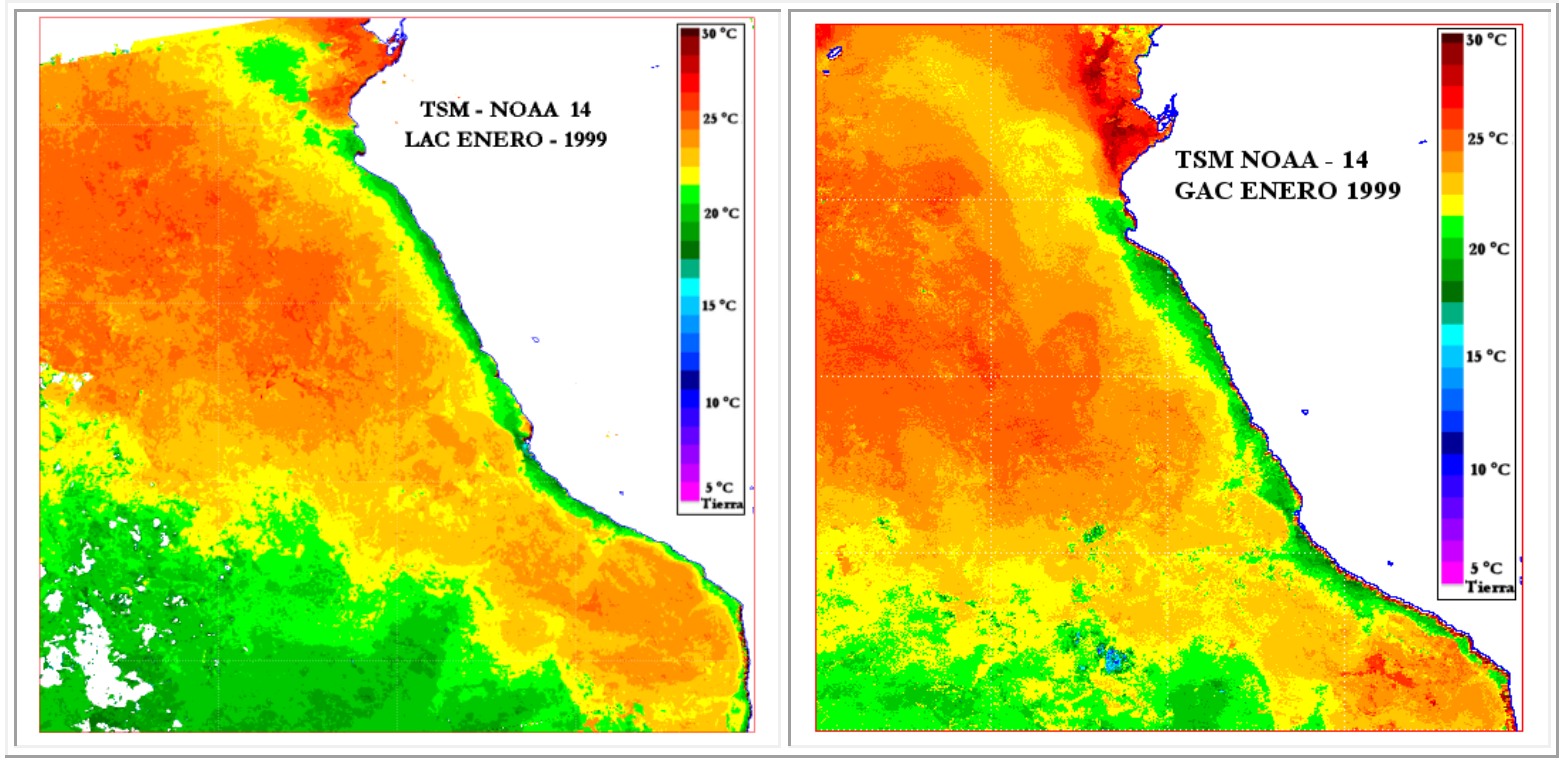

Fig. 2. (a) Imagen TSM promedio mensual de enero 1999 (2.2 km); y (b) Imagen TSM compuesto mensual enero $1999(4.4 \mathrm{~km})$.

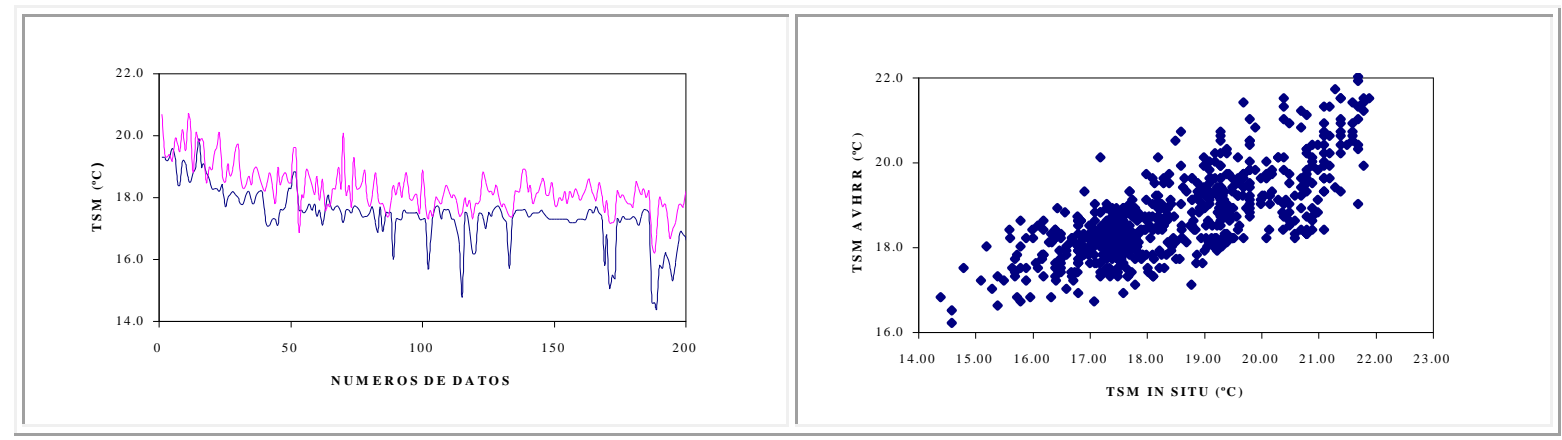

Fig. 3. (a) Comparación de las TSM medidos por satélite (violeta) y los TSM medidos in situ (azul) (panel izquierda). (b) Diagrama de dispersión de las TSM medido por satélite y TSM medido in situ (panel derecha).

En la Fig. 3a se muestra la relación entre la TSM medida por satélite y medida in situ. Las medidas estadísticas utilizadas para comparar las estimaciones realizadas a partir de imágenes de 
satélite y las mediciones in situ son el promedio de las medidas de TSM por satélite, el promedio de las medidas de TSM in situ, desviación de los datos, el RMSD y el coeficiente de correlación.

La Tabla 1 da algunos valores estadísticos importantes para cada una de las muestras. Como se muestra en la Tabla 2 los valores promedios de los dos grupos de medidas se desvían $0.3^{\circ} \mathrm{C}$ y corresponden a un error de $1.6 \%$. La desviación estándar de cada una de las muestras, nos proporciona información sobre la dispersión de los valores con respecto al valor promedio.

En la Tabla 1, también, se muestra que la dispersión de los valores de la TSM medido por satélite es menor que la dispersión de los de los valores de TSM medidas in situ por la cantidad $1.42{ }^{\circ} \mathrm{C}$. Por otro lado los valores de la varianza de cada una de las muestras nos proporciona información sobre la variabilidad de los datos, en nuestro caso la TSM medida in situ tiene mayor variabilidad que las medidas de la TSM por satélite. El RMSD para nuestros datos es $1.07^{\circ} \mathrm{C}$.

Tabla 1 - Valores estadísticos de la validación

\begin{tabular}{|l|c|c|}
\hline Resultados Estadísticos & TSM $^{\text {in-situ }}$ & TSM $^{\text {satelite }}$ \\
\hline Promedio & $18.4^{\circ} \mathrm{C}$ & $18.7^{\circ} \mathrm{C}$ \\
\hline BIAS & \multicolumn{2}{|c|}{$0.3^{\circ} \mathrm{C}(+1.6 \%)$} \\
\hline Desviación Estándar & 1.5 & 0.98 \\
\hline Varianza & 2.4 & 0.96 \\
\hline Correlación & \multicolumn{2}{|c|}{0.75} \\
\hline RMSD & \multicolumn{2}{|c|}{$1.07^{\circ} \mathrm{C}$} \\
\hline
\end{tabular}

En la Figura 3(b) se muestra la relación entre la TSM medido por satélite y medido in situ, la distribución de los datos tiende a una distribución lineal. El grado de linealidad esta dado por el coeficiente de correlación entre estas dos muestras (si el coeficiente de correlación es 1 la distribución es completamente lineal). el coeficiente de correlación entre los datos de la TSM por satélite y la TSM medida in situ nos permite determinar la relación entre estos dos conjuntos de datos y examinar la linealidad de los datos. El coeficiente de correlación para nuestros datos es de 0.75

Además, se han obtenido imágenes TSM compuestos desde enero 2000 hasta diciembre 2003. (ver Fig. 4). En las imágenes TSM mensual se muestra un aumento de la TSM en los meses de enero hasta abril, siendo los meses de febrero y marzo los meses con las mas altas temperaturas. De mayo a octubre los valores de TSM empiezan a descender, siendo agosto con la mas baja temperatura. Estos meses están caracterizados por alta nubosidad. En los meses de noviembre y diciembre la temperatura empieza a incrementarse nuevamente. Los meses con las más altas temperatura se dieron en febrero 2000, marzo 2001, marzo 2002, marzo 2003 y febrero 2004. De estos el año con las temperaturas más altas fue 2001.

\section{Conclusiones}

En el presente trabajo se ha obtenido la TSM diarios y compuestos mensuales a partir de los datos imágenes originales Level $1 \mathrm{~b}$ del sensor AVHRR / NOAA $(14,15-17)$ con un resolución espacial de $1,1 \mathrm{~km}$ para imágenes tipo LAC y 4,4 $\mathrm{km}$ para imágenes tipo GAC.

Se ha diseñado el software Pacha Ricaj para procesar de forma rápida y eficiente las imágenes AVHRR/NOAA GAC y LAC. En este software se han integrado algoritmos de procesamiento inicial, procesamiento, realces y análisis de las imágenes.

Se ha obtenido la TSM a partir de las imágenes del sensor AVHRR/NOAA con un error de 0.3 ${ }^{\circ} \mathrm{C}(1.6 \%)$. Las imágenes TSM muestran una alta variabilidad en los tres años de estudio (2000 2003). En los meses de agosto setiembre y octubre existe alta nubosidad. Más métodos están pendientes para aplicarlos a las TSM. 

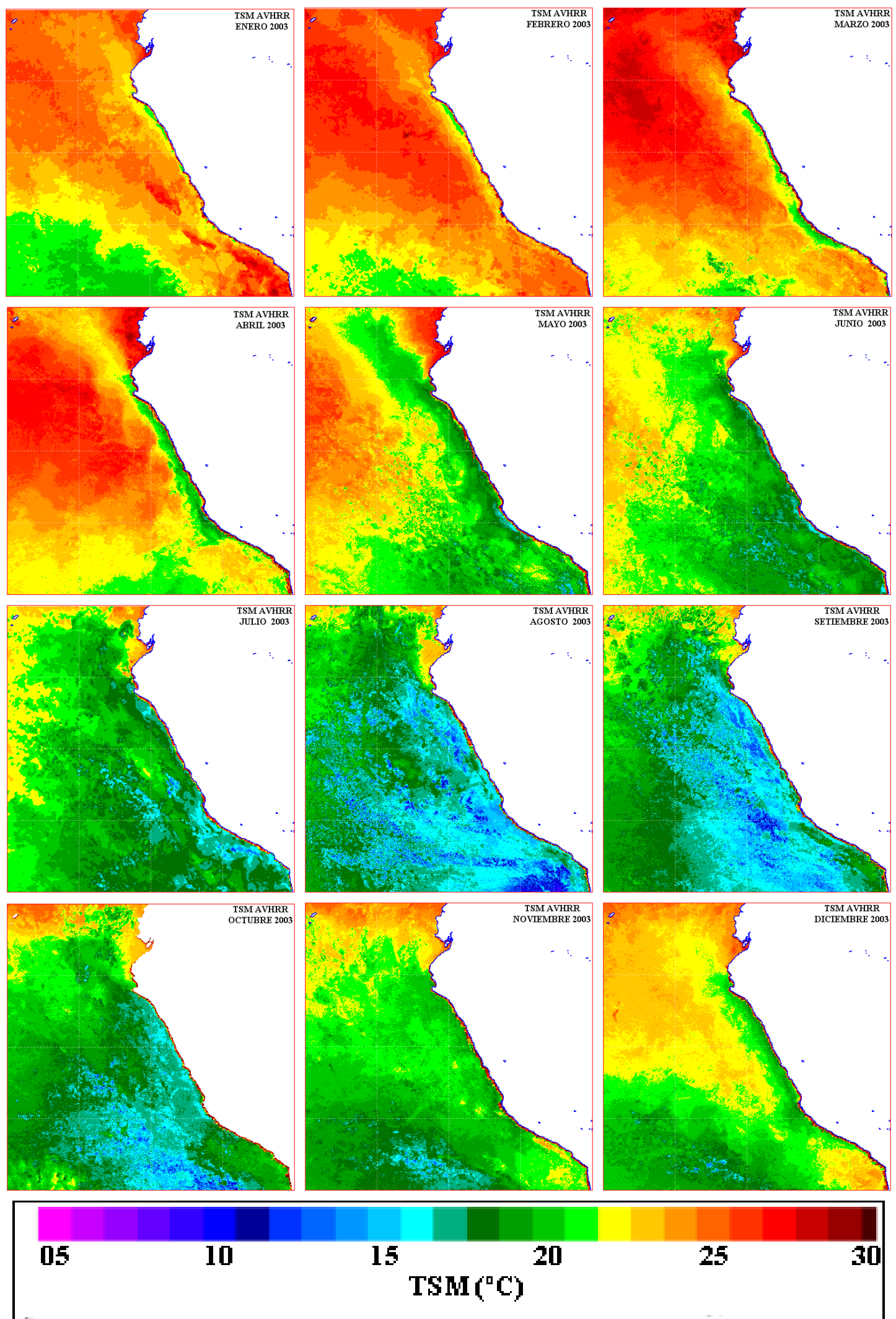

Fig. 4. Serie temporal de imágenes TSM compuestos del año 2003 


\section{AGRADECIMIENTOS}

Este trabajo fue posible gracias al apoyo económico de la Agencia Española de Cooperación Internacional durante los periodos de los años 2000/2001, 2001/2002 y 2002/2003. Expresamos nuestro agradecimiento al CONCYTEC por su apoyo económico al financiar nuestro proyecto de investigación en el año 2001-2002. También agradecemos a la NOAA y al IMARPE por sus datos AVHRR en formatos level 1b y HRPT respectivamente disponibles para este trabajo. Finalmente agradecemos al Consejo Superior de Investigaciones de la UNMSM por su valioso apoyo durante los periodos 2002 y 2003.

\section{Referencias}

[1] Anding, D.; Kauth, R. Estimation of sea surface temperature from space. Remote Sensing of Environment 1, 217-220, 1970.

[2] Stevenson, R.E. Oceanographic applications and limitations of satellite remote sensors, Bull. Am. InsNt. Aeronaut. Astronaut., 7(2), 1970.

[3] Martin, J. Parametrización y análisis del territorio para gestión del hábitat en conservación. Tesis Doctoral, Departamento de Física Aplicada. Universidad de Vigo, 2002

[4] McClain, E. P.; Pichel, W. G.; Walton, C. C.. Comparative performance of AVHRR based multichannel sea surface temperatures, J. Geophys. Res., 90, 11587 11601, 1985.

[5] McMillan, L. M.; Crosby, D. S. Theory and validation of the multiple window sea surface temperature technique, J. Geophys. Res., 89(C3), 3655-3661, 1984.

\section{IMARPE, 2003.}

[7] Smith, E., et al. Satellite-Derived Sea Surface Temperature Data Available from the NOAA/NASA Pathfinder Program, http://www.agu.org/eos_elec/95274e.html, (c) 1996 American Geophysical Union.

[8] Brown, Otis B.; James W. Brown; Robert H. Evans. Calibration of Advanced very high resolution radiometer infrared observations, J. Geophys.. Res., 90, 11667-11677, 1985.

[9] Eche, J.C. Estimación de la temperatura de la superficie del mar a partir de las imágenes AVHRR / NOAA. Tesis de maestría en Física, Informe Técnico Labtel. FCF-UNMSM, Lima-Perú, 2004.

[10] Rojas J.; Eche J. C. la temperatura de las superficie del mar a partir de imágenes del sensor AVHRR del satélite de orbita polar NOAA-14. Revista de Investigación de Física, Vol. 4, No 1, 2001

[11] Rojas J. La Temperatura de la superficie del mar en el océano pacifico oriental del hemisferio sur a partir de la imágenes del sensor AVHRR/2 del satélite de orbita polar NOAA-14. SELPER, 2002.

[12] Glantz, M.H. Why care about El Niño and La Niña, chapter 8 in Satellites, Oceanography and Society, D. Halpern (ed), Elsevier Oceanography Series, pp. 149-170, 2000.

[13] Carr, M.E.; Broad, K. Satellites, society, and the Peruvian fisheries during the 1997 - 1998 El Niño, chapter 9 in Satellites, Oceanography and Society, D. Halpern (ed), Elsevier Oceanography Series, pp. 149-170, 2000. 